\title{
"Hot" and active particles in alluvial soils and sediments of the Yenisei river: Radioisotope composition
}

\author{
F.V. Sukhorukov, M.S. Melgunov and A.V. Chuguevsky \\ Institute of Geology and Mineralogy SB RAS, 630090 Novosibirsk, Russia
}

\begin{abstract}
New data on abundance and isotope composition of "hot" and active particles in alluvial soils and sediments of the Yenisei river (Krasnoyarsk region, Russia), located in a near influence zone of the Krasnoyarsk Mining and Chemical Processing Plant (KMCPP), are presented in this study. On a set of gamma-emitting radioisotopes all "hot" particles can be divided on three groups: 1 . monoisotopic $\left({ }^{137} \mathrm{Cs}\right.$, $\left.{ }^{60} \mathrm{Co}\right)$; 2. two-isotopic $\left({ }^{137} \mathrm{Cs}\right.$ and $\left.{ }^{134} \mathrm{Cs}\right)$; 3. polyisotopic $\left({ }^{137} \mathrm{Cs},{ }^{134} \mathrm{Cs},{ }^{60} \mathrm{Co},{ }^{154} \mathrm{Eu},{ }^{155} \mathrm{Eu}\right.$ and $\left.{ }^{241} \mathrm{Am}\right)$. Very significant is the absence of ${ }^{152} \mathrm{Eu}$ in all polyisotopic particles whereas in soils this isotope is often predominant. The active particles are presented by the several polyisotopic types, containing: $1 .{ }^{154} \mathrm{Eu}$, ${ }^{155} \mathrm{Eu},{ }^{137} \mathrm{Cs},{ }^{60} \mathrm{Co}$ and ${ }^{241} \mathrm{Am} ; 2 .{ }^{154} \mathrm{Eu},{ }^{155} \mathrm{Eu},{ }^{137} \mathrm{Cs}$ and ${ }^{241} \mathrm{Am} ; 3 .{ }^{152} \mathrm{Eu},{ }^{154} \mathrm{Eu},{ }^{155} \mathrm{Eu},{ }^{60} \mathrm{Co}$ and ${ }^{241} \mathrm{Am}$ and monoisotopic $\left({ }^{60} \mathrm{Co}\right.$ and $\left.{ }^{137} \mathrm{Cs}\right)$. Presence of the active particles containing all isotopes, except of ${ }^{137} \mathrm{Cs}$, and particles without ${ }^{152} \mathrm{Eu}$ and ${ }^{60} \mathrm{Co}$ is interesting. Some active particles due to their set of radioisotopes can be referred to the finely dispersed fragments of the «hot»particles. However, the majority of them have the nature distinct from the "hot" particles.
\end{abstract}

\section{INTRODUCTION}

It is well-known that the significant part of the radionuclides released as a result of various nuclear events has been associated with particles. Radioactive or "hot" particles were got into environment during nuclear weapon tests, accidents with nuclear reactors and plants, at use of ammunition with depleted uranium. Particles are also released in authorized and nonauthorized discharges from reprocessing plants and associated radioactive wastes. Therefore, releases of radioactive particles have occurred more frequently than perhaps usually anticipated [1-3].

Investigations carried out within last ten years have shown, that alluvial soils and sediments of the Yenisei river situated in flood-lands of the river valley downstream the KMCPP are contaminated by "hot" and active particles of various type [4-7]. The "Hot" particles with activities in the range of $n \cdot 10^{4}$ to $\mathrm{n} \cdot 10^{6} \mathrm{~Bq}$ per particle are spread rarely enough (60-70 particles per $\mathrm{km}^{2}$ ). So their contribution to the total contamination of the alluvial soils and sediments is rather low. At the same time having much lower activities ( $\mathrm{n}-\mathrm{n} \cdot 10^{3} \mathrm{~Bq}$ per particle) the active particles are spread very widely. Their contribution to the total contamination is significant and attains up to $20-100 \%$ for different isotopes and types of alluvial formations.

The main objective of the given work is to generalize the last results received by authors during the study of the "hot" and active particles, which are typical for the contaminated soils and sediments of the Yenisei river.

\section{MATERIALS AND METHODS}

\subsection{Sampling procedures}

More than 30 "hot" particles has been found out and sampled for research in alluvial soils of islands and the right bank of the Yenisei in the near influence zone of the KMCPP $(\sim 20 \mathrm{~km}$ downstream the discharge point) by authors for the last eleven years: 5 of them in 2005, 3 in 1998, 1 in 2001, 3 in 2004, 
4 in 2005, 1 in 2006 and 14 in 2007. All found out "hot" particles were strong gamma-emitters. In field conditions their presence was fixed by significant increase of an exposure rate in the points of their finding in the contaminated soils. As a rule, the "hot" particles occurred in the upper layers of the soils on the depth no more than $10 \mathrm{~cm}$. The particles were sampled together with a containing substratum and their final allocation was spent already in laboratory conditions. Unlike the "hot" particles, the active particles have the significantly lower activities. It was practically impossible to find out them in the field conditions. So some samples of large volume (5-15 liters) of alluvial soils and sediments were taken on the contaminated areas for further study of the active particles occurrence and features.

\subsection{Analytical procedures}

All analytical procedures connected with the study of the "hot" and active particles, were carried out in laboratories of the IGM SB RAS. Definition of the isotopic composition and activities of the gammaemitting radionuclides was carried out by the gamma-spectrometetric method with the use of the HPGe coaxial and planar detectors. Plutonium isotopes $\left({ }^{239,240} \mathrm{Pu}\right.$ and $\left.{ }^{238} \mathrm{Pu}\right)$ were determined by means of traditional alpha-spectrometric method. Study of morphology, phase and chemical composition of the "hot" particles was carried out by the use of the scanning electron microscope (SEM) LEO1430VP supplied with an energy-dispersion analysis spectrometer "OXFORD".

\section{RESULTS AND CONCLUSIONS}

\section{1 "Hot" particles}

Preliminary results of investigation of fourteen "hot" particles which have been found out during field works in 2007 are presented in this study. Characteristics of radio-isotope composition of these particles are given in Table 1. Additional study of four selected particles (Gch-14 (a), Gch-9 (b), Gch-12 (c) and Gch-6 (d)) was carried out by use of the scanning electron microscope (see Figs. 1 and 2). On the isotope composition of the gamma-emitting radionuclides (see Table 1), the shape and the sizes (see Fig. 1) all these particles are typical for those found out in the contaminated alluvial soils of the Yenisei earlier $[4,5,7]$.

Practically in all particles ${ }^{137} \mathrm{Cs}$ is dominating radionuclide. An exception is the cobalt "hot" particle (Gch-1). Its gamma activity is completely connected with ${ }^{60} \mathrm{Co}(33600 \mathrm{~Bq})$. Activities of ${ }^{239,240} \mathrm{Pu}$ and ${ }^{238} \mathrm{Pu}$ were determined for particles Gch-5 and Gch-9. The corresponding measured values are: 0.55 and $3.41 \mathrm{~Bq}$ for particle Gch-9; 35.7 and $1025 \mathrm{~Bq}$ for particle Gch-5. It is necessary to note the high ${ }^{238} \mathrm{Pu} /{ }^{239,240} \mathrm{Pu}$ ratios in both particles: 6.2 and 28.7 respectively.

On a set of gamma-emitting radioisotopes all "hot" particles can be divided in to three groups:

1) monoisotopic (only ${ }^{137} \mathrm{Cs}$ or ${ }^{60} \mathrm{Co}$ );

2) two-isotopic $\left({ }^{137} \mathrm{Cs}\right.$ and $\left.{ }^{134} \mathrm{Cs}\right)$;

3) polyisotopic $\left({ }^{137} \mathrm{Cs},{ }^{134} \mathrm{Cs},{ }^{60} \mathrm{Co},{ }^{154} \mathrm{Eu},{ }^{155} \mathrm{Eu}\right.$ and $\left.{ }^{241} \mathrm{Am}\right)$.

It is very important to emphasize the fact of absence of ${ }^{152} \mathrm{Eu}$ in all polyisotopic particles whereas in the ambient soils this isotope is often predominant. Many "hot" particles of the Yenisei, which were found out by their enrichment in gamma-emitting radionuclides, contain uranium oxides. The uranium oxides grains and clusters of grains are included in matrixes of the "hot" particles (see Fig. 2). Almost all "hot" particles contain a lot of carbon, and some are presented by graphite. All above-listed factors specify the fuel or reactor origin of the Yenisei "hot" particles.

Detection in 2007 of fourteen "hot" particles in the upper layer $(0-10 \mathrm{~cm})$ of alluvial soils in the near influence zone of the KMCPP specifies their additional ingress in the last two years and, accordingly, possible increase of density of their distribution. Moreover, if to assume, that the ratio of activities of ${ }^{137} \mathrm{Cs}$ and ${ }^{134} \mathrm{Cs}$ is connected with particle's "age", then this ratio variations (see Table 1) testify to intermediate storage of the "hot" particles before their entrance to the Yenisei. 
Table 1. Radionuclide composition of fourteen "hot" particles.

\begin{tabular}{|c|c|c|c|c|c|c|c|}
\hline \multirow{2}{*}{$\begin{array}{l}\text { Particle } \\
\text { number }\end{array}$} & \multicolumn{6}{|c|}{ Activity, Bq/particle } & \multirow{2}{*}{$\frac{{ }^{137} \mathrm{Cs}}{{ }^{134} \mathrm{Cs}}$} \\
\hline & ${ }^{137} \mathrm{Cs}$ & ${ }^{134} \mathrm{Cs}$ & ${ }^{154} \mathbf{E u}$ & ${ }^{155} \mathbf{E u}$ & ${ }^{60} \mathrm{Co}$ & ${ }^{241} \mathrm{Am}$ & \\
\hline Gch-1 & nd & nd & nd & nd & 32300 & nd & \\
\hline Gch-2-1 & 22170 & 27 & 465 & 160 & 12 & 1115 & 821 \\
\hline Gch-2-2 & 104600 & nd & nd & nd & nd & 15 & \\
\hline Gch-4-2 & 8500000 & nd & nd & nd & nd & nd & \\
\hline Gch-11 & 425900 & nd & 319 & nd & 104 & 1571 & \\
\hline Gch-12 (c) ${ }^{* *)}$ & 79130 & 110 & 2040 & 588 & 51 & nd & 719 \\
\hline Gch-13-1 ${ }^{*)}$ & 11440 & 16 & 272 & 81 & 13 & 5 & 715 \\
\hline Gch-13-2*) & 16410 & 27 & 383 & 100 & 17 & 11 & 608 \\
\hline Gch-13-3*) & 36180 & 50 & 860 & 230 & 33 & 21 & 724 \\
\hline Gch-14 (a) ${ }^{* *)}$ & 29210 & nd & 232 & 125 & 11 & 2650 & \\
\hline Gch-10 & 59640 & 40 & 137 & nd & nd & nd & 1491 \\
\hline Gch-9(b) ${ }^{* *)}$ & 217000 & nd & nd & nd & nd & nd & \\
\hline Gch-5 & 102600 & 148 & 3080 & 849 & 88 & 91 & 693 \\
\hline Gch-6(d) $)^{* *)}$ & 14070 & 9 & 170 & 51 & 10 & 809 & 1563 \\
\hline Gch-7 & 45100 & 64 & 1402 & 417 & 50 & 36 & 705 \\
\hline Gch-8 & 49930 & nd & 65 & nd & 7 & nd & \\
\hline
\end{tabular}

nd - not detected (below the detection limit)

*) - parts of one particle

${ }^{* *}-$ four particles involved in the SEM study.
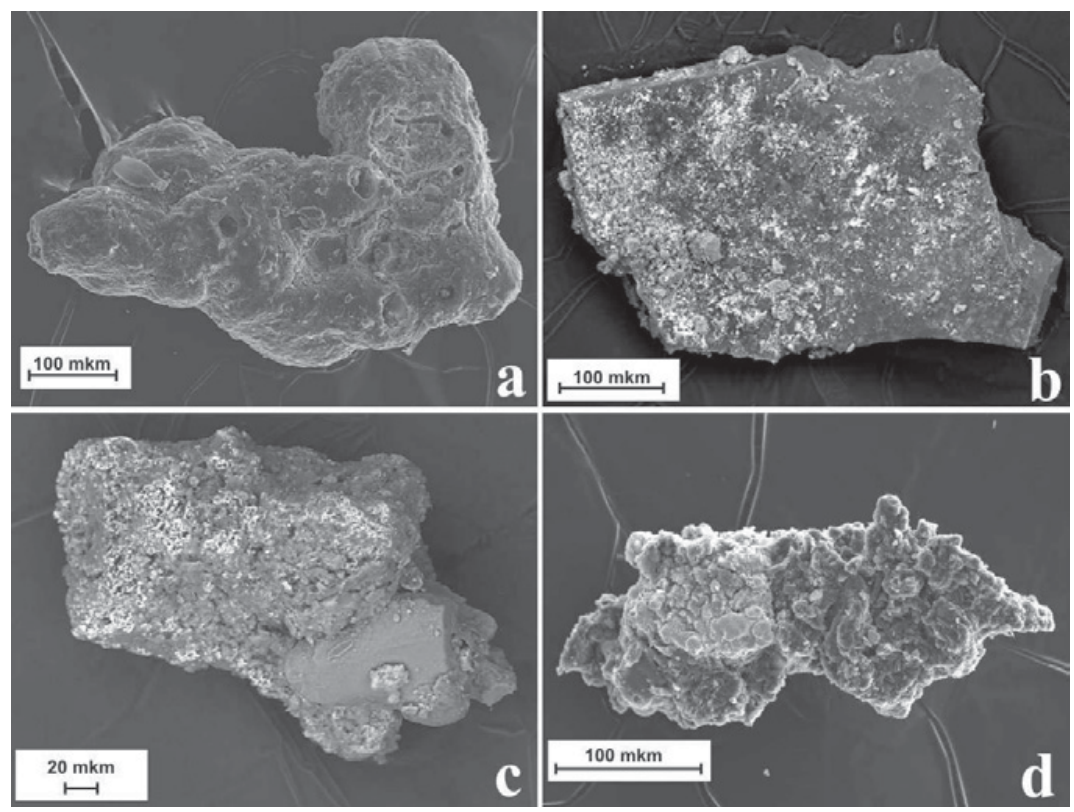

Figure 1. Appearance and dimension of four selected "hot" particles (see Table 1, SEM): a) Gch-14 (560 mkm); b) Gch-9 (520 mkm); c) Gch-12 (290 mkm); d) Gch-6 (350 mkm).

\subsection{Active particles}

The active particles or the "hot" particles of 2 nd kind have been earlier revealed and described in the literature $[6,7]$ for the contaminated soils of the Atamanovsky island $(10 \mathrm{~km}$ from discharge, point 3 in Table 2). Besides this point we studied the active particles in several samples of other contaminated 

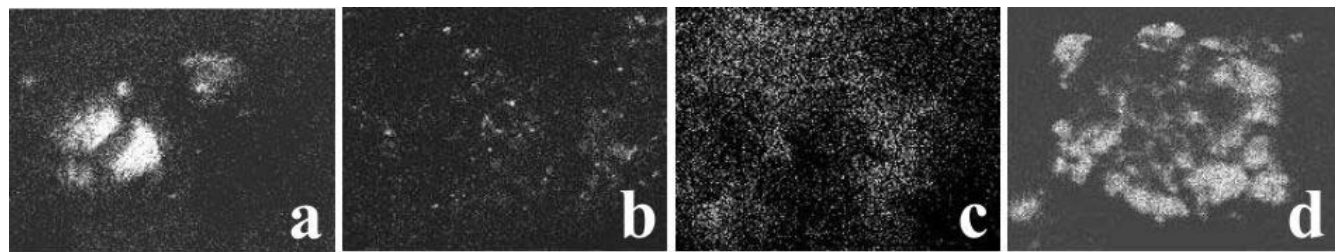

Figure 2. Uranium in the "hot" particles (see Table 1 and Fig. 1, mapping made by SEM with EDS).

alluvial formations (see Table 2): point 1 -soil of the island located in immediate proximity from a place of discharge; point 2-sediment taken at the right bank of the Atamanovsky island (near point 3). The typical spatial distribution of specific activities of the gamma-emitting radionuclides in the sample of the sediment (point 2) is presented on Fig. 3. Similar distribution is observed for all studied alluvial soils (points 1 and 3 ).

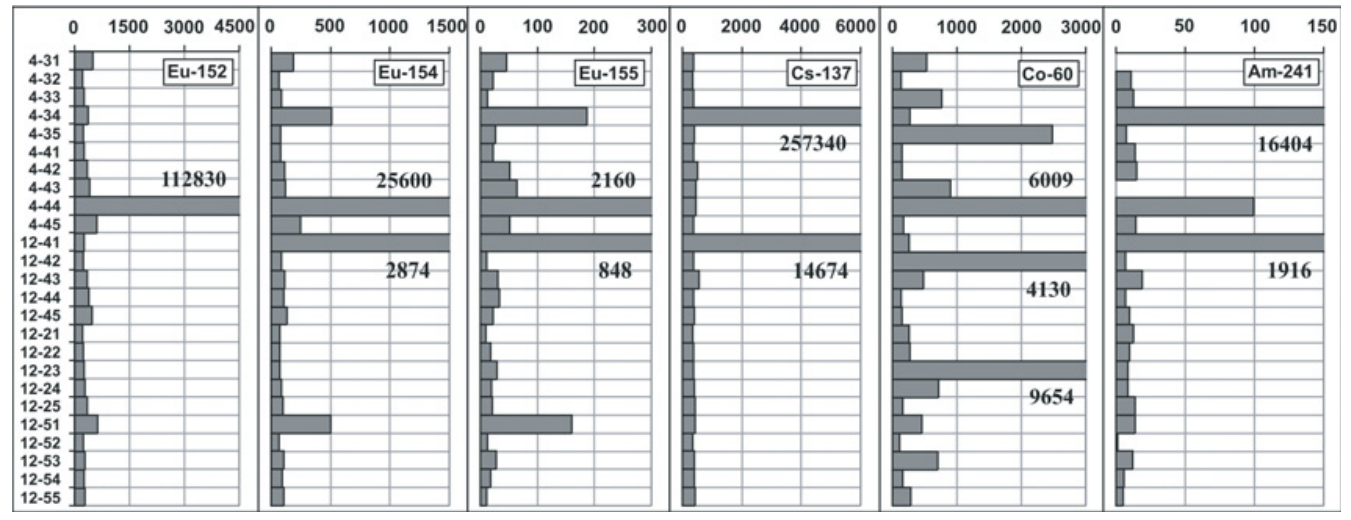

Figure 3. Spatial distribution of activities (in $\mathrm{Bk} / \mathrm{kg}$ ) of the gamma-emitting radionuclides in the sample of the contaminated sediment (point 2 , the results of the measurements of $1 \mathrm{~g}$ weight samples).

On a set of gamma-emitting radioisotopes all active particles can be divided on:

- polyisotopic groups, containing:

1) ${ }^{154} \mathrm{Eu},{ }^{155} \mathrm{Eu},{ }^{137} \mathrm{Cs},{ }^{60} \mathrm{Co}$ and ${ }^{241} \mathrm{Am}$;

2) ${ }^{154} \mathrm{Eu},{ }^{155} \mathrm{Eu},{ }^{137} \mathrm{Cs}$ and ${ }^{241} \mathrm{Am}$;

3) ${ }^{152} \mathrm{Eu},{ }^{154} \mathrm{Eu},{ }^{155} \mathrm{Eu},{ }^{60} \mathrm{Co}$ and ${ }^{241} \mathrm{Am}$;

- monoisotopic group $\left({ }^{60} \mathrm{Co}\right.$ or $\left.{ }^{137} \mathrm{Cs}\right)$.

Presence of the active particles containing all isotopes, except of ${ }^{137} \mathrm{Cs}$, and particles without ${ }^{152} \mathrm{Eu}$ and ${ }^{60} \mathrm{Co}$ is interesting. Some active particles due to their set of radioisotopes can be referred to as finely dispersed fragments of «hot»particles. However, the majority of them have the nature distinct from the "hot" particles.

In the Table 2 estimated values of the contribution of the active particles in the general contamination of the alluvial soils and sediments, received for the studied points in the near influence zone of the $\mathrm{KMCPP}$, are presented. 
Table 2. The contribution of the active particles to the general contamination of the alluvial soils and sediments of the Yenisei river (the near influence zone of the KMCPP), \%.

\begin{tabular}{|l|l|l|l|l|l|l|}
\hline Points of sampling & ${ }^{152} \mathrm{Eu}$ & ${ }^{154} \mathrm{Eu}$ & ${ }^{155} \mathrm{Eu}$ & ${ }^{137} \mathrm{Cs}$ & ${ }^{60} \mathrm{Co}$ & ${ }^{241} \mathrm{Am}$ \\
\hline Point 1 (1 km from discharge, soil) & 61 & 55 & 73 & 21.3 & 70 & 80 \\
\hline Point 2 (10 km from discharge, sediment) & 54 & 43 & 81 & 34 & 76 & 100 \\
\hline Point 3 (10 km from discharge, soil) & 74 & 70 & & 45 & 73 & \\
\hline Point 3 (10 km from discharge, soil [6]) & & 42 & & 72 & $33-100$ & $95-100$ \\
\hline
\end{tabular}

\section{Acknowledgments}

The work was executed at financial support of the Integration Project of the Siberian Branch of the Russian Academy of Sciences No. 30.

\section{References}

[1] B. Salbu. J. of Environ. Radioactivity, 53 (2001) 267-268.

[2] A.V. Byhovsky and O.M. Zaraev "Hot" airborne particles in technical use of atomic energy (Moscow, Atomizdat, 1974) 254 p. (in Russian).

[3] B. Salbu and O.C. Lind. Radioprotection, Supple. 1, 40 (2005) s27 - s32.

[4] A.Ya Bolsunovsky, T.A. Goraychenkova, V.O. Tcherkezian and B.F. Myasoedov. Radiokhimiya, 40 (2000) 271-274.

[5] A.Ya Bolsunovsky and V.O. Tcherkezian. J. of Environ. Radioactivity, 57 (2001) 167-174.

[6] Z.G. Gritchenko, Yu.V. Kuznetsov, V.K. Legin, V.N. Strukov, B.F. Myasoedov, A.P. Novikov, A.E. Shishlov and Yu.V. Savitskii. Radiochemistry, 43 (2001) 639-642.

[7] F.V. Sukhorukov, A.G. Degermendzhy, V.M. Belolipetsky, A.Ya Bolsunovsky, S.I. Kovalev, K.U. Kosolapova, M.S. Melgunov and V.F. Raputa. Distribution and migration of radionuclides in the Yenisei plain (Novosibirsk: Publ. House of SB RAS, Dep. “Geo”, 2004) 286 p. 
